\title{
Design of Campus Financial Risk Prevention and Control Platform under the Background of Big Data
}

\author{
Sijin $\mathrm{Li}^{1 *}$ \\ ${ }^{1}$ School of Economics and Management, Dalian University of Science and Technology Dalian, Liaoning, 116052, China
}

\begin{abstract}
With the continuous development of information technology and the gradual rise of the Internet financial industry, the incidence of campus fraud is higher and higher, and the financial fraud against college students has gradually attracted widespread attention. In order to study the risk prevention and control factors of College Students' financial fraud under the background of big data, an information platform is established to release risk information in real time and analyze the risk factors of College Students' financial fraud. The Internet, big data and campus financial risk prevention and control are combined to improve the financial environment of university campus, improve the prevention awareness of college students, and reduce unnecessary losses.
\end{abstract}

\section{Introduction}

Internet finance is a financial industry represented by the Internet, mainly including mobile payment, cloud computing, online lending platform, etc. The Internet financial model reduces the degree of market information asymmetry. Both sides of the transaction only need to bear the lower capital term matching cost and risk sharing cost, and can directly realize the issuance and transaction of stocks, bonds and loans on the Internet. In addition, people's payment in this financial mode becomes more convenient, and the two sides of the supply and demand of funds can realize direct transaction. Therefore, since 2010, China's Internet finance has made great progress. Mobile payment and lending platform have gradually replaced cash and credit card and become the mainstream payment method.

As a new online lending platform, $\mathrm{P} 2 \mathrm{P}$, which has the advantages of simple and fast online lending, has sprung up. Because of this, many P2P and other online financial services platform businesses are very attractive to college students, catering to the consumption needs of some college students. A few years ago, the university credit market, which was silent due to the suspension of university students' credit cards, is now being rekindled by internet financial lending. In addition, the emergence of online shopping and financial management makes college students' Internet financial transactions more frequent. According to the data, the scale of College Students' Internet consumer financial transactions increased by $746.7 \%$ year on year in 2015. Therefore, in terms of Internet consumption, the group represented by college students is a major object of Internet consumption. However, because college students do not have independent economic ability, the ability to resist financial risks is poor. In addition, many college students live on campus for a long time and do not have much contact with the society, so their ability to judge financial fraud needs to be improved. Especially it is difficult to distinguish various financial fraud means, such as financial management, identity counterfeiting, marketing illegal business and so on.

In recent years, there are many cases of abnormal consumption of College Students' online lending. Financial fraud against college students will not only cause information leakage, cause certain economic losses and neglect of their studies, but also affect the stability of families and schools, resulting in serious adverse consequences. Therefore, financial fraud for college students should follow the background of "Internet plus". We should use information network technology to build a platform for financial risk prevention and control, and improve the financial environment of university campus with the help of new technologies such as live big data and cloud computing.

\section{Common Types of Financial Fraud of College Students}

We have a total of 500 questionnaires on College Students' financial fraud. The contents of the questionnaire include the basic information of college students, the types of financial fraud encountered, the amount of fraud, the treatment measures taken after being cheated, and the possible preventive measures. The survey data shows that "part-time swindle" accounts for $20.9 \%$ of the total types of fraud, which is the most common way of being swindled in the investigated projects, "fake friend fraud" also accounts for a large part, accounting for $11.3 \%$ of the total survey. The rest of the more common projects are "false winning", "SMS fraud" and so on. The proportion

*Corresponding author's e-mail: lisijin@dlust.edu.cn 
of "loan inducement fraud" among college students is only $5.35 \%$.

From the above results, it can be seen that as more and more college students want to be independent, the desire of part-time job is more and more strong, and the information of part-time job will appear in the advertisements of many websites. The overwhelming advertisements make it difficult to distinguish the true from the false. Therefore, College students who are eager to earn extra money by part-time job are easily cheated. In addition to part-time jobs, "fake friend fraud" also accounts for a large part, which is a huge disadvantage of information leakage. In today's society, with the advent of the information age, the rapid development of Internet has led to more and more personal information being leaked. Among them, telephone numbers, name and even ID number may be exploited by fraudulent groups, and then cheat through such ways as impersonating friends or relatives to borrow money. College Students are relatively simple, and are easily defrauded by trust in friends or relatives. Money, therefore, we need to be vigilant to prevent fraud. It is worth noting that the proportion of "loan inducement fraud" has decreased significantly. In this survey, loan inducement fraud only accounts for about $5 \%$, indicating that a large number of $\mathrm{P} 2 \mathrm{P}$ credit platforms have been exposed in recent years, and college students have a more correct understanding of it. In addition, since 2017, the Ministry of education has explicitly banned any Internet loan behavior against college students in a press conference. Therefore, under the control of the central government, the campus loan risk faced by college students has been effectively suppressed, and the possibility of college students being cheated in order to consume in advance has been reduced.

There are many opportunities for college students to encounter financial fraud, mainly in four periods:

- After the freshmen are admitted, they hope to be ready for the university life, so the prospective college students begin to contact the seniors and sisters through various social software and forums. However, there is no certain safeguard measures and screening for such information. Once the criminals impersonate the seniors and sisters, the prospective college students who have no conditional trust may encounter financial fraud.

- When freshmen enter the new environment, it's easy to leak information and trust strangers. This is the time when financial fraud is most easy to succeed. It's easy for lawbreakers to break the psychological defense line of college students and carry out fraud activities.

- When you sign up for CET-4 or CET-6 or postgraduate entrance examination, you can't avoid getting all kinds of certificates and diplomas. Everywhere on the campus, we can see information such as "guaranteed CET-4 or CET-6" with the contact information of the other party. College students who blindly believe in it are likely to be cheated and lose money.

- During the job-hunting period, college students may also be cheated, especially when they are seeking parttime jobs on the Internet. It is difficult to identify the true and false advertisements, so they may be cheated, causing economic losses and even affecting personal safety.

\section{Construction scheme of financial risk prevention and control platform in Colleges and Universities}

Promoting the financial risk prevention and control platform in Colleges and universities is the inevitable choice for the innovation and development of campus risk prevention and control under the social background of "Internet +", and also the only way to further promote the scientific level of financial risk prevention and control in Colleges and universities. The financial risk prevention and control platform of colleges and universities is an innovation of applying Internet information technology to the financial fraud prevention work of colleges and universities.

\subsection{University financial risk prevention and control information announcement platform}

The information announcement platform mainly uses the means of "Internet + " informatization to carry out information publicity of financial risk prevention and control in Colleges and universities, release campus fraud information and prevention and control measures in real time, such as fraud means, amount of fraud, preventive measures, etc., describe the information of each link in the process of fraud, and provide reporting telephone.

The information announcement platform of financial risk prevention and control in Colleges and universities is used to transfer all information release from offline to online to form data collection and information release at the same time.

\subsection{Background data analysis platform}

Through the information collected by the front desk of financial risk prevention and control, the financial risk archives are established according to the categories, the financial risk data are analyzed and processed, the campus financial risk prevention and control model is established, the financial risk is quantified, the financial risk is prevented and controlled at different levels, and some high risk prevention and control are pre warned in advance.

\subsection{University financial risk prevention and control learning platform}

Learning platform for financial risk prevention and control in Colleges and Universities: the learning platform can provide a service platform for education, training and communication for teachers and students. Through this module, teachers and students can learn the knowledge and methods of financial risk prevention and control. When they study, educate, train and work, they can record the key content anytime and anywhere, which can improve the awareness of risk prevention and control of teachers and students in Colleges and universities and effectively reduce the risk Financial fraud. 


\subsection{University financial risk prevention and control service platform}

Financial risk prevention and control service platform in Colleges and Universities: the service platform is the progress of solving financial fraud, through which the cheated teachers and students can find out the progress of their own cases; the platform is not only a tool and means to manage financial fraud, but also a bridge between the school and the injured teachers and students, making the school's service more full of human care. According to the principles of convenience, efficiency and affinity, the construction scheme of financial risk prevention and control platform in Colleges and universities is explored. The construction scheme of this paper is shown in Figure 1.
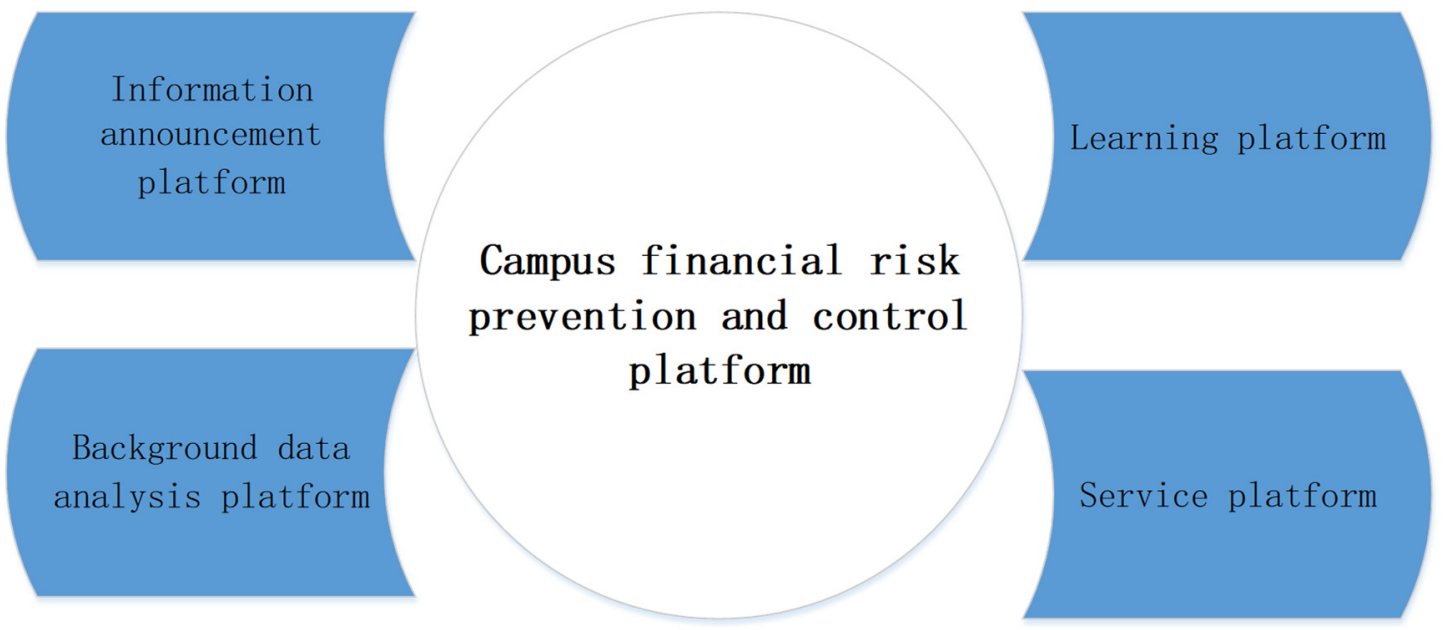

Figure 1. Construction scheme of financial risk prevention and control platform in Colleges and Universities

Module analysis: build the financial risk prevention and control platform in Colleges and universities, further strengthen the prevention and early warning measures of our university, departments and teachers and students on the basis of the traditional financial fraud prevention and control system, and adhere to the principle of "data integration, linkage analysis, accurate service". The Internet plus big data technology has been used to build a platform for financial risk prevention and control in Colleges and universities, so as to realize the organic synergy between online and offline and comprehensively promote the synchronous construction of financial risk prevention and control in universities.

The specific functions of the sub platform are as follows:

- Information platform -- establish an online platform for financial risk prevention and control in Colleges and universities to realize the financial risk early warning and preventive measures from centralized to decentralized, from offline to online, so that teachers and students can understand the campus financial fraud trends in real time and improve their awareness of prevention in real time;

- Background data analysis platform -- improve the financial fraud information, with the steady expansion of the number of financial fraud in Colleges and universities year by year, improve the financial fraud prevention and control mechanism, establish financial fraud files, and simultaneously use big data technology to realize the statistical analysis of the number, amount and category of fraud, and improve the dynamic management of education and training of teachers and students' awareness of financial fraud prevention;

- Learning platform -- education and training module, the establishment of regular expert lectures, online lectures, set up live channels, encourage everyone to watch online, so that the financial risk prevention and control education work of college teachers and students is three-dimensional, diverse and full coverage;

- Service platform -- Internet service module, through the financial risk prevention and control platform of colleges and universities, to build a public service platform integrating teachers and students' services.

\section{4 conclusions}

In the era of big data, college students are facing many financial security risks, which need to be prevented. Through the establishment of big data platform, we can effectively improve college students' financial security awareness, correctly understand and understand financial knowledge, strengthen the understanding of financial products, financial system and financial fraud means, enhance vigilance and reduce the possibility of being cheated. At the same time, we should pay attention to protect personal information and prevent fraud caused by personal information leakage. In addition, college students should consume moderately according to their own situation, avoid greed by all means, and establish a correct concept of consumption, so as not to give opportunities to criminals.

\section{Acknowledgments}

This work was supported by the General Project of Educational Science Planning in Liaoning Province (JG17DB078). 


\section{References}

1. Kang, Q.. (2019). Financial risk assessment model based on big data. International Journal of Modeling Simulation \& Scientific Computing, 10(04), 106-113.

2. Niu S. Prevention and supervision of internet financial risk in the context of big data[J]. Revista de la Facultad de Ingenieria, 2017, 32(11):721-726.

3. Lan K. Financial Risk Control of Sports Industry Based on Big Data[J]. Journal of Physics Conference Series, 2020, 1648:042068.

4. Ayala C, Fang J, Escobedo L, et al. Actions to Control High Blood Pressure Among Hypertensive Adults in Texas Counties Along the Mexico Border: Texas BRFSS, 2007[J]. Public Health Reports, 2012, 127(2):173-185.

5. Xingbing F. Research on Financial Risk Management of Electronic Supply Chain Based on Big Data Technology[J]. Journal of Guangdong Industry Polytechnic, 2018.

6. Ning K, Donghui J. Risk prevention and control of Internet finance[J]. Journal of Liaoning Technical University (Social Science Edition), 2019. 